\section{Microsatellite Libraries Enriched for Several Microsatellite Sequences in Plants}

\section{BioTechniques 20:758-760 (May 1996)}

Simple sequence repeats (SSRs), or microsatellites, have been isolated and characterized from numerous animal and plant species $(6,7)$. These sequences have been shown to be highly polymorphic between individuals within populations or closely related genotypes. This, together with the fact that they can be converted into a simple polymerase chain reaction (PCR)based assay, has led to their widespread use as molecular markers of genetic diversity (6). The use of microsatellites has been limited in plants, however, by the costs involved in isolating large numbers from the target species. Recently, a number of papers have reported the isolation of microsatellite clones by an enrichment procedure $(1,2,4,5)$. These reports have all resulted in the isolation of a single type of microsatellite. However, as little is known about the level of polymorphism of individual microsatellite sequences, it is possible that this approach will result in markers that do not detect the level of polymorphism often required in diversity studies. Furthermore, the targeting of a single microsatellite species may produce only a small number of clones necessitating the construction of further libraries in the future. To eliminate these problems, we have significantly modified the enrichment technique $(2,5)$ to yield clones that contain a variety of microsatellites. These clones can then be characterized by either direct sequencing or colony hybridization using specific microsatellite oligonucleotides. Interestingly, the technique also yields a high percentage of clones containing more than one type of microsatellite. Results to date suggest that the clones produced by this procedure are sufficiently polymorphic to be used in population genetics and/or breeding studies.

Preparation of reagents for microsatellite enrichment. The following oligonucleotides can be used to en-
Table 1. Frequency of Different Microsatellite Sequences in the Multiplex Libraries

\begin{tabular}{|ccc|}
\hline $\begin{array}{c}\text { Type of } \\
\text { microsatellite }\end{array}$ & $\begin{array}{c}\text { Frequency of microsatellite as a \% of the total } \\
\text { number of clones containing a microsatellite }\end{array}$ & $\begin{array}{c}\text { Average } \\
\text { repeat length }\end{array}$ \\
\hline GT & 30 & 18 \\
GA & 20 & 20 \\
CGG & 10 & 10 \\
CCA & 5 & 8 \\
CATA & 5 & 30 \\
Compound & 30 & 25 \\
\hline
\end{tabular}

rich for DNA fragments containing microsatellites: $[\mathrm{GA}]_{15},[\mathrm{GT}]_{15},[\mathrm{AT}]_{15}$, $[\mathrm{GC}]_{15},[\mathrm{CAA}]_{10},[\mathrm{CATA}]_{10},[\mathrm{ATT}]_{10}$, $[\mathrm{GATA}]_{10},[\mathrm{GCC}]_{10}$ and $[\mathrm{ATAG}]_{10}$. Fifty nanograms of each oligonucleotide in $3 \times \mathrm{SSC}(45 \mathrm{mM}$ sodium citrate, $\mathrm{pH} 7.0$ and $450 \mathrm{mM} \mathrm{NaCl}$ ) are pooled in a total volume of $80 \mu \mathrm{L}$, spotted onto a $0.5-\mathrm{cm}^{2}$ piece of Hybond ${ }^{\circledR} \mathrm{N}^{+}$ (Amersham, Arlington Heights, IL, USA) and air-dried for $1 \mathrm{~h}$. The dry membrane is UV-treated for $30 \mathrm{~s}$ using a 260-nm transilluminator. Weakly bound oligonucleotides are washed off the membrane by washing twice in 10 $\mathrm{mL}$ of hybridization buffer $(50 \%$ formamide, $3 \times$ standard saline citrate [SSC], 25 mM Na-phosphate, pH 7.0, and $0.5 \%$ sodium dodecyl sulfate [SDS]) at $45^{\circ} \mathrm{C}$ for 2 days. The membranes are then stored at $-20^{\circ} \mathrm{C}$ until required.

Preparation of genomic DNA. One microgram of genomic DNA is digested with 2 units of $R s a \mathrm{I}$ in a volume of $20 \mu \mathrm{L}$ for $1 \mathrm{~h}$ at $37^{\circ} \mathrm{C}$. Fifty nanograms

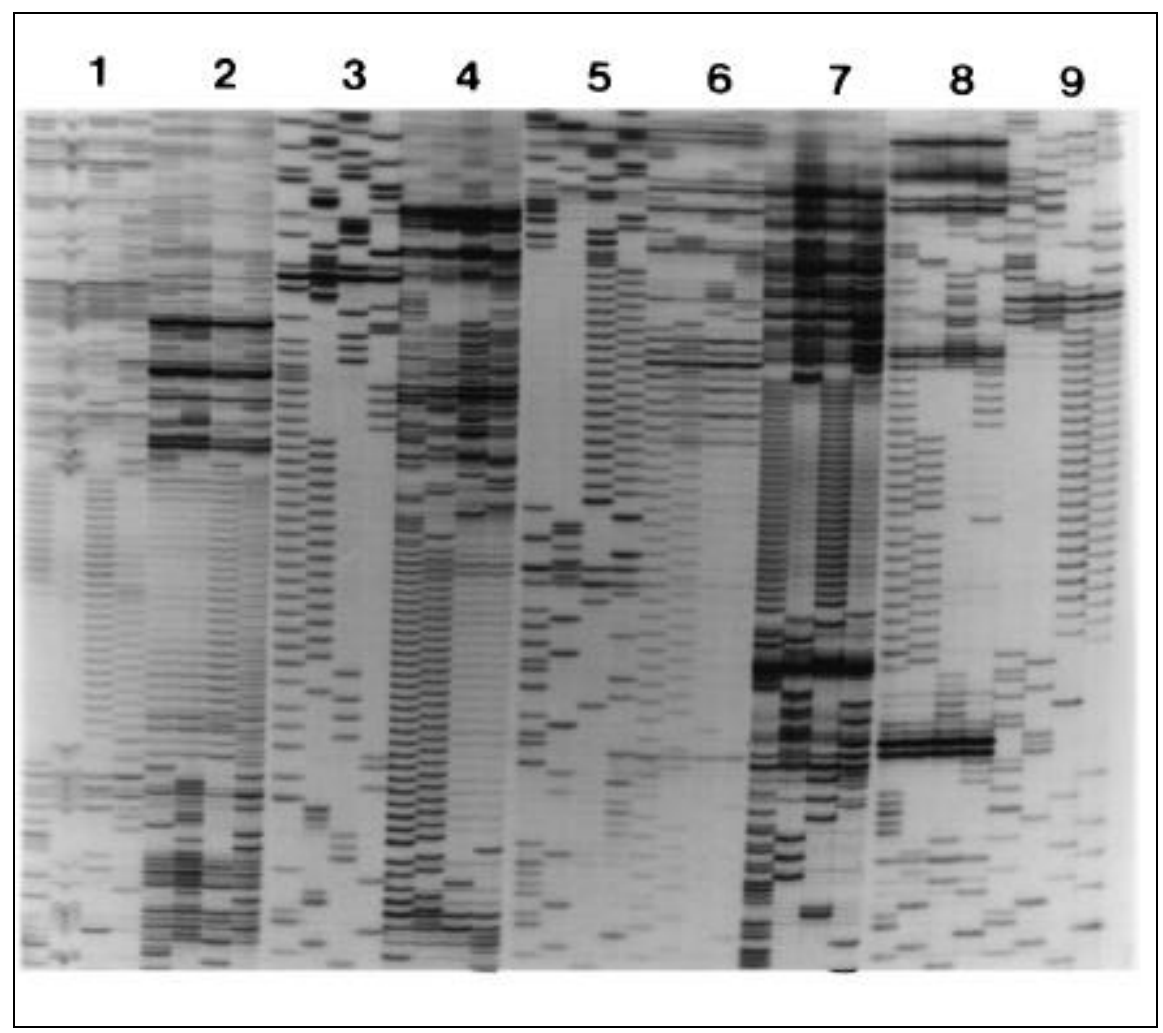

Figure 1. Sequence analysis of nine microsatellites clones. Nine clones were chosen at random from a number of plant DNA libraries enriched for microsatellites and sequenced using the universal forward primer. Autoradiography was performed on the dried sequencing gel for $18 \mathrm{~h}$ at room temperature. Samples were loaded onto the gel in the order ACGT. 
of an $M l u I$ adaptor (consisting of a 21mer: 5'CTCTTGCTTACGCGTGGACTA3' and a phosphorylated 25-mer: 5'pTAGTCCACGCGTAAGCAAGAGCACA3') together with $2 \mu \mathrm{L} 10 \mathrm{mM}$ ATP are added to the digestion mixture along with 1 unit of $\mathrm{T}_{4}$ DNA ligase. Ligation is then allowed to proceed for $2 \mathrm{~h}$ at $37^{\circ} \mathrm{C}$. Finally, the ligated DNA is denatured by boiling for $5 \mathrm{~min}$.

Enrichment of microsatellites. Enrichment for microsatellites is carried out using $100 \mathrm{ng}$ of the ligated, denatured DNA in $500 \mu \mathrm{L}$ of hybridization buffer containing $2 \mu \mathrm{g}$ of the 21 -mer oligonucleotide (5'CTCTTGCTTACGCGTGGACTA3') using a single Hybond $\mathrm{N}^{+}$filter with bound oligonucleotides for $24 \mathrm{~h}$ at $37^{\circ} \mathrm{C}$. Following hybridization, the filter is washed $20 \times$ ( 5 min per wash) in $0.5 \times \mathrm{SSC}$ at $65^{\circ} \mathrm{C}$. Bound DNA is then eluted in $200 \mu \mathrm{L}$ sterile distilled water by boiling for 5 min. One microliter of the eluted DNA is amplified by PCR using the 21-mer adaptor primer in $25 \mu \mathrm{L}$ of $1.5 \mathrm{mM}$ $\mathrm{MgCl}_{2}, 200 \mu \mathrm{M}$ each dATP, dCTP, dGTP and TTP, $1 \times$ reaction buffer and 1 unit Taq DNA Polymerase (Life Technologies, Gaithersburg MD, USA). Amplification is allowed to proceed for 20 cycles $\left(94^{\circ} \mathrm{C}\right.$ for $40 \mathrm{~s}, 60^{\circ} \mathrm{C}$ for $60 \mathrm{~s}$ and $72^{\circ} \mathrm{C}$ for $120 \mathrm{~s}$ ) in a Stratagene Robocycler ${ }^{\mathrm{TM}}$ (Stratagene, La Jolla, CA, USA), after which the enrichment step and amplification are repeated once more using all of the material generated from the previous step.

Characterization of enriched microsatellites. Approximately $2.5 \mathrm{ng}$ of enriched DNA were taken directly from the final amplification, digested with 1 unit of MluI and ligated into $10 \mathrm{ng}$ of a modified pUC19 vector (pJV1) containing a $B s s \mathrm{HI}$ site (K.J. Edwards, unpublished results). Inclusion of $M l u \mathrm{I}$ in the ligation ensures that each plasmid contains only a single insert. Plasmids are transformed into DH10B ${ }^{\mathrm{TM}}$ (Life Technologies) and plated onto L-agar plates containing $100 \mu \mathrm{g} / \mathrm{mL}$ ampicillin. Following incubation overnight at $37^{\circ} \mathrm{C}$, colonies are transferred into microplates for long-term storage. Plasmids from individual colonies are prepared using the Promega Wizard ${ }^{\mathrm{TM}}$ kit (Madison, WI, USA) and sequenced using Sequenase ${ }^{\circledR}$ Version 2 (United States Biochemical, Cleveland, OH, USA).
This protocol was developed as part of an EC-funded collaborative project (3) in which the facile construction of microsatellite-enriched libraries from a variety of plant species was desired. To date, the procedure has been used successfully to prepare enriched libraries for DNA from maize, willow, rhododendron, barley, sunflower, sugarbeet, wheat and diploid wheat. The procedure is quick and relatively inexpensive in that it does not require the biotinylation of the oligonucleotides used to select the microsatellites. It also results in the production of large numbers of clones. These clones can be organized as an ordered array at high density using a Biomek ${ }^{\circledR}$ workstation (Beckman Instruments, Fullerton, CA, USA) and probed with the individual microsatellite oligonucleotides. This procedure would allow the operator to identify all the clones containing a particular type of microsatellite for further characterization. Sequencing of at least 10 clones chosen at random from each of the libraries (140 clones in total) has confirmed that they are highly enriched for microsatellite sequences with between $50 \%$ and $70 \%$ of the clones containing at least one microsatellite (Figure 1). Sequencing has also shown that the insert size ranges from $250 \mathrm{bp}$ to $900 \mathrm{bp}$. To date, sequence comparison of the enriched clones from the various libraries has shown that there is no evidence for a selective enrichment of specific sequences. Detailed characterization of 15 clones containing microsatellites including the synthesis of flanking primers and amplification from a selection of genotypes has shown that in every case a microsatellite containing amplification product of the expected size is produced. Furthermore, 13 of the 15 primer pairs used produced polymorphic bands in several of the genotypes tested (K.J. Edwards, unpublished results). Interestingly, a significant proportion of the clones contain two or more different microsatellite sequences. We have identified clones containing all of the oligonucleotides bound to the Hybond $\mathrm{N}^{+}$ (Table 1) with the exception of the ATAG oligonucleotide. This last observation suggests that many more different microsatellite sequences probably exist within the genome of most plant and animal species. Taken together, the results suggest that the clones produced by this procedure are both representative of the original genomic sequences and sufficiently polymorphic to be used in population genetics and/or breeding studies.

\section{REFERENCES}

1.Armour, J.A.L., R. Neumann, S. Gobert and A.J. Jeffreys. 1994. Isolation of human simple sequence repeat loci by hybridisation selection. Hum. Mol. Genet. 3:599-605.

2.Karagyozov, L., I.D. Kalcheva and V.M. Chapman. 1993. Construction of random small-insert genomic libraries highly enriched for simple sequence repeats. Nucleic Acids Res. 21:3911-3912.

3.Karp, A. and D.S. Ingram. 1995. Biotechnology, biodiversity and conservation. Bio/Technology 13:522.

4.Kijas, J.M.H., J.C.S. Fowler, C.A. Garbett and M.R.Thomas. 1994. Enrichment of microsatellites from the citrus genome using biotinylated oligonucleotide sequences bound to streptavidin-coated magnetic particles. BioTechniques 16:657-662.

5.Ostrander, E.A., P.M. Jong, J. Rine and G. Duyk. 1992. Construction of small-insert genomic DNA libraries highly enriched for microsatellite repeat sequences. Proc. Natl. Acad. Sci. USA 89:3419-3423.

6.Tautz, D. 1989. Hypervariability of simple sequences as a general source for polymorphic DNA. Nucleic Acids Res. 17:6463-6471.

7.Wang, Z. J., L.Weber, G. Zhong, and S.D. Tanksley. 1994. Survey of plant short tandem DNA repeats. Theor. Appl. Genet. 88:1-6.

The authors wish to thank Ian Blain from Zeneca Seeds, Bracknell, Berkshire, England, UK for the synthesis of the oligonucleotides used in this study. This work was carried out as part of the EC Biotechnology Program Grant No. B102 CT-930295. Address correspondence to Keith J. Edwards, IACR-Long Ashton Research Station, Department of Agricultural Sciences, University of Bristol, Long Ashton, Bristol BS18 9AF, UK. Internet: keith.edwards@bbsrc.ac.uk

Received 18 September 1995; accepted 17 November 1995.

K.J. Edwards, J.H.A. Barker, A. Daly, C. Jones and A. Karp University of Bristol Bristol, England, UK 